TANNIER C., FOLTÊTE J-C., GIRARDET X. (2012), Assessing the capacity of different urban forms to preserve the connectivity of ecological habitats, Landscape and Urban Planning, vol. $105, n^{\circ} 1-2$, pp. 128-139.

\title{
Assessing the capacity of different urban forms to preserve the connectivity of ecological habitats
}

Cécile TANNIER, research associate* (cecile.tannier@univ-fcomte.fr) - corresponding author Jean-Christophe FOLTÊTE, professor* (jean-christophe.foltete@univ-fcomte.fr)

Xavier GIRARDET, PhD student* (xavier.girardet@univ-fcomte.fr)

\author{
* ThéMA, CNRS - University of Franche-Comté \\ 32 rue Mégevand \\ F-25 030 Besançon cedex France \\ Tel : +33 381665481 \\ Fax: +33 381665355
}

\begin{abstract}
This paper addresses the relationship between anthropogenic forest habitat fragmentation and the form of urban patterns. Using a two-step methodology we first generate 40 theoretical residential development scenarios following a repeatable procedure; the simulated urban forms are either moderately compact or fractal. Then, we compare the scenarios according to the functional connectivity of the remaining forest habitat using a graph-based approach. The methodology is applied to the urban region of Besançon (France), where forest surfaces are considered as a generic habitat for several animal species. Results obtained show that fractal scenarios of residential development are almost equivalent to moderately compact scenarios regarding the connectivity of forest habitat when the residential development is weak. In the case of a more intense residential development, fractal scenarios are superior to nonfractal scenarios when low dispersal distances of animals are concerned.
\end{abstract}

\section{Introduction}

Managing urban sprawl is a major concern of urban planning. Its negative effects on the environment are indeed of great significance: air pollution, noise, destruction of natural resources. From a socio-economic point of view, the negative effects of urban sprawl are also worrying: increase of the cost of housing and travel, leading to social segregation and social inequity. Yet urban development is a real necessity in many countries due to the increase of the number of inhabitants and households. Consequently, the question of land consumption is a major planning stake. Knowing that land consumption for new residential buildings is often 
moderate when compared to consumption for road infrastructures (Camagni et al., 2002), the recurring question is: where to locate urban extensions without increasing the negative effects of urban sprawl?

One important impact of urban sprawl on natural ecosystems is the fragmentation of wildlife habitats (Forman, 1995). The growth of artificial surfaces reduces the available habitats through the loss of favorable areas and the division of the remaining habitat areas into separated patches. In a fragmented habitat, the viability of a species depends on the ability of individuals to reach one patch from another by crossing unsuitable habitat. Consequently, landscape connectivity, combined with the size and the quality of habitat patches, proves to be a key notion for the conservation of animal species. Along with structural connectivity, functional connectivity is recognized as being most relevant from an ecological point of view (Taylor et al., 2006). Functional connectivity can be defined as the interaction between a given species and the elements of a landscape. Methods for assessing the functional connectivity often use landscape metrics (Magle et al., 2009) or spatial simulation models (Tischendorf and Fahrig, 2000). In order to set up tools which are easy to use by planners and landscape managers, we turned to graph theory, which provides an interesting compromise between the intensive need for measurements in a biological approach and the constraints linked to data acquisition (Calabrese and Fagan, 2004; Fall et al., 2007). Moreover, graph theory is a preferable alternative to spatially explicit population models for species conservation in heterogeneous landscapes (Minor and Urban, 2007).

While numerous studies have analyzed responses of animals to anthropogenic habitat fragmentation, few researches have addressed the relationship between this process and the form of urban patterns. As expressed by Alberti (2005), we do not know how clustered versus dispersed and monocentric versus polycentric urban structures differently affect environmental conditions, nor how urban development patterns influence ecological systems along the gradient of decreasing density from urban center to periphery. Alberti (2005) also emphasized that ecological studies dealing with urbanization simplify the consideration of urban structures to such an extent that the results of are no longer useful to urban planners and managers. For example, Tratalos et al. (2007) have confronted several density measures with a series of measures of environmental quality and biodiversity potential. Their study lead to no conclusive 
results and showed that similar urban forms may induce a varying environmental quality. Geurs and van Wee (2006) have used a system called Environment Explorer, in which land use and transport modules are dynamically linked to simulate scenarios of urban development. The $500 \mathrm{~m}$ resolution of the land use cells, however, was too coarse for exact measurements of environmental impacts at the local level. The limited transfer of knowledge between the ecophysical and the spatial planning domains, underlined by Termorshuizen et al. (2007), may partly explain the lack of knowledge about the relationship between urban forms and ecological functioning.

In this paper, we aim to reach a better understanding of this relationship by exploring how different patterns of residential development may impact the form of animal habitats, and therefore affect their connectivity. Two categories of built patterns are considered: compact built patterns characterized by high built densities, uniformity, and clear (i.e. non sprawling) boundaries (Geurs and van Wee, 2006); fractal built patterns that are intrinsically non uniform throughout the scales, and exhibit longer and more sinuous boundaries compared to compact patterns (Frankhauser, 2004). In the field of urban planning, the compact city model is the common answer to the problem of urban sprawl (Dantzig and Saaty, 1973). But the limits of this model have been shown (Breheny, 1992), and the current trend is to promote the "wisely compact” (Camagni et al., 2002) well-organized polycentric city. The fractal city model, in keeping with this tendency, appears to be promising since several authors have suggested that the fractal city could satisfy people who consume various urban and rural amenities by improving access to both built-up and non built-up spaces (Cavailhès et al., 2004; Frankhauser, 2004). Some ecological implications of fractal patterns of ecological habitat have also been demonstrated (Milne, 1991).

In this paper, we adopted a two-steps methodology. First, we generate forty theoretical scenarios of residential development following a repeatable procedure that explicitly takes into account fractal or nonfractal urban development models. Then, we compare the scenarios according to the functional connectivity of the remaining habitat using a graph-based approach. Our aim is to identify the urban model which best preserves the habitat connectivity. 


\section{Study area and data}

The study area includes the city of Besançon and its metropolitan area located in the eastern part of France (Fig. 1). With a surface area of 116827 ha, the study area numbers about 234000 inhabitants. Except for the urban core, the study area is not densely urbanized but urbanization tends to grow. This situation allows the creation by simulation of many scenarios of residential development.

Fig. 1. Metropolitan area of Besançon, France $\left(47^{\circ} 14^{\prime} \mathrm{N}, 6^{\circ} 01^{\prime} \mathrm{E}\right)$

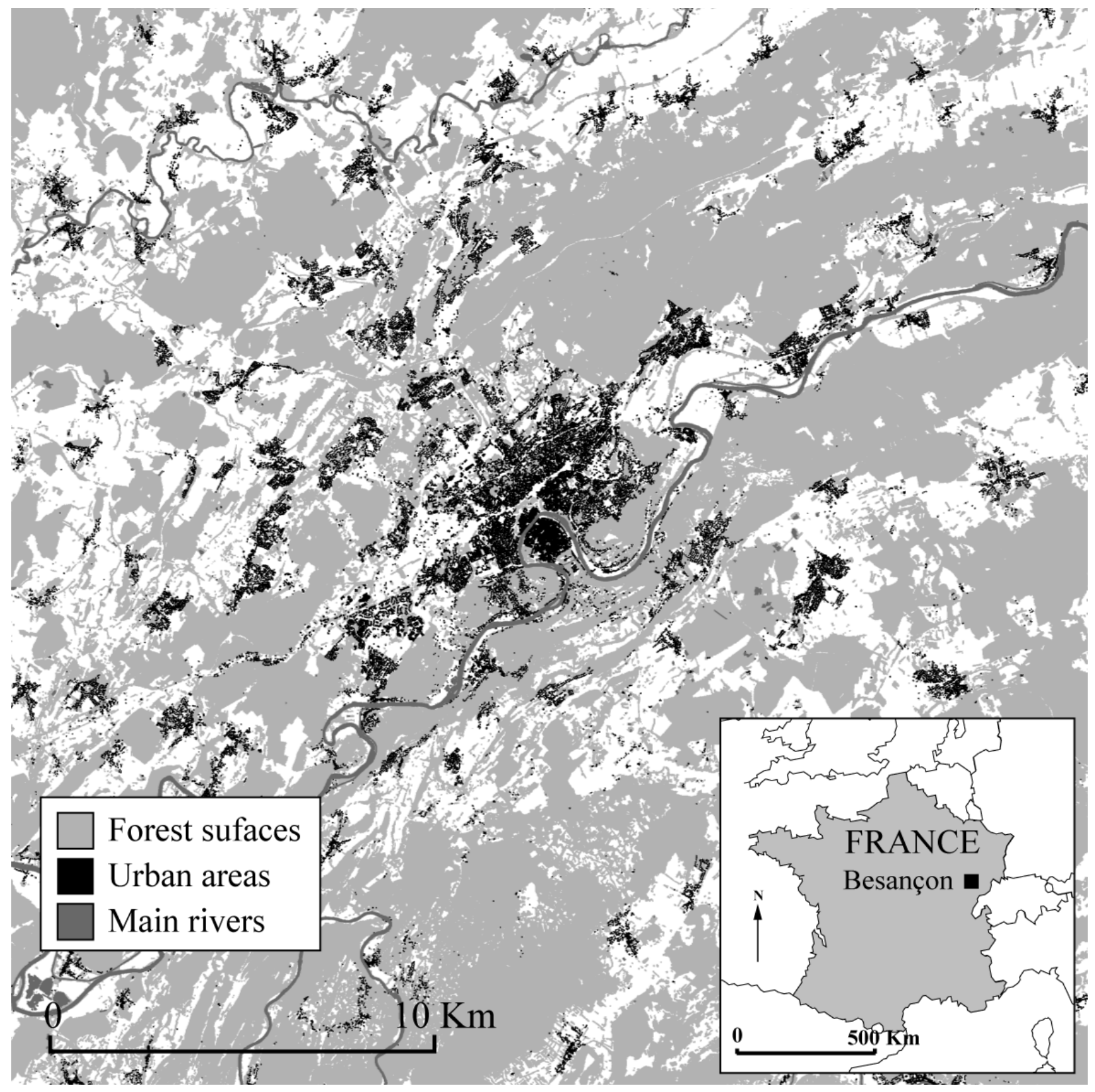


Forested zones, threatened by urban sprawl, dominate the landscape. They represent a relevant ecological habitat for several mammal species with home range included in the study area. We have selected some of these species using the Red List of the International Union for the Conservation of Nature (IUCN, 2010), which includes habitats and threats classification schemes for threatened species. Species retained in our study are the Western Barbastelle (Barbastella barbastellus), the Fallow Deer (Dama dama), the Common Genet (Genetta genetta), the Lynx (Lynx lynx), the European Pine Marten (Martes martes), and the Schreiber's Bat (Miniopterus schreibersii). Those species share the following characteristics: (1) they preferentially use forested landscape elements; (2) they have difficulties to move in non forest landscapes; and (3) they are threatened by the extension of built areas.

Land-cover data used are derived from the 'BD Topo' vector database provided by the Institut Géographique National (IGN 2009, BD TOPO ${ }^{\circledR}$

http://professionnels.ign.fr/ficheProduitCMS.do?idDoc=5667214). The 'BD Topo' includes forest and building surfaces as well as the road network. Maps of forest habitat were obtained by rasterizing the forest layer of the 'BD Topo'. To preserve a high level of spatial detail, rasterizing was performed at a resolution of $20 \mathrm{~m}$ (0.04 ha per grid cell).

\section{Generation of scenarios of residential development}

Forty scenarios of residential development have been created using the software MUP-City 0.5.3 (Tannier et al., 2010). MUP-City allows to generate residential development scenarios starting from an existing built pattern. The creation of new residential locations is simulated, but not the creation of new roads that often accompanies them. As its input, MUP-city requires two types of data: the detailed road network (lines) and the buildings (polygons). As output, MUP-City provides a raster map with three types of cells: initially built-up, newly built-up (simulated) and non built-up (natural or artificial land uses).

The simulated scenarios may take into account two planning rules. The first rule sets that each new residential cell has to be located close to both a nonbuilt cell and a built cell in order to be interesting for residential development; moreover, building the cell must not hamper the access to open spaces for neighboring built-up cells. This planning rule is supposed to satisfy household 
preferences by offering a rural environment while ensuring possible interactions with neighboring households (Caruso et al., 2007). It also answers two planning objectives, which are reduce car trips (for accessing open spaces), and limit landscape fragmentation.

The second planning rule sets that new residential cells have to be as close as possible to existing roads in order to limit space consumption. Indeed consumption of land for road infrastructure is extremely high: 25\% of the total urban area in Europe and 30\% in the United States (Camagni et al., 2002).

Formalization of the two planning rules is based on assessment criteria taking the form of fuzzy variables ranging from 0 (bad) to 1 (good). For rule \#1 'Proximity to built-up and open spaces', the assessment criterion is the number of non built-up cells around each built-up cell directly contiguous to the assessed cell (in a $3 \square 3$ Moore neighborhood). A fuzzy variable $\mu(x)$ describes the assessment criterion through a membership value to the fuzzy set 'good' evaluation: $\mu(x)=x / 34$ with $\mu(x) \in[0 ; 1]$, and $\mathrm{x}$ being the number of non built-up cells contiguous to at least one non built-up cell in the neighborhood of the assessed cell.

This formulation refers to the fact that a cell counts no more than 34 non built-up cells in its $3 \square 3$ neighborhood.

The assessment criterion for rule \#2 'Proximity to existing roads' is the distance to the closest road. When the assessed cell is either crossed by a road or close to a road the value of the assessment criterion is 1 , and it diminishes as the distance (measured in cells) grows.

According to the scenarios, either one or two of the planning rules have been applied. Results obtained are either one or two assessment values comprised between 0 and 1 . The arithmetic mean of these values gives a synthetic evaluation of the interest of each cell for residential use. Ultimately, the system selects dynamically the cells it would be most beneficial to urbanize. When there is a tie between cells, the choice of one or the other is made randomly. 


\section{Fractal scenarios of residential development}

For the creation of fractal development scenarios, planning rules have been applied considering a series of nested scales. Initially, the study area is covered by a regular coarse-grained grid. Each grid square contains a fixed number of cells determined by a reduction factor r. We then apply a multi-scale modeling that consists in reducing the size of the grid square from one level of analysis to the next (Fig. 2). Initially, the grid square size is $l_{1}$. At the next level of analysis, each grid square of size $l_{1}$ is subdivided into grid squares of size $l_{2}$, corresponding to the cells of level $l_{1}$.

$$
l_{2}=(1 / r) l_{1}
$$

This procedure of decomposing the grid squares into cells is reiterated until the cell size is close to that of the buildings (here $20 \mathrm{~m}$ ).

Fig. 2. Multi-scale spatial modeling
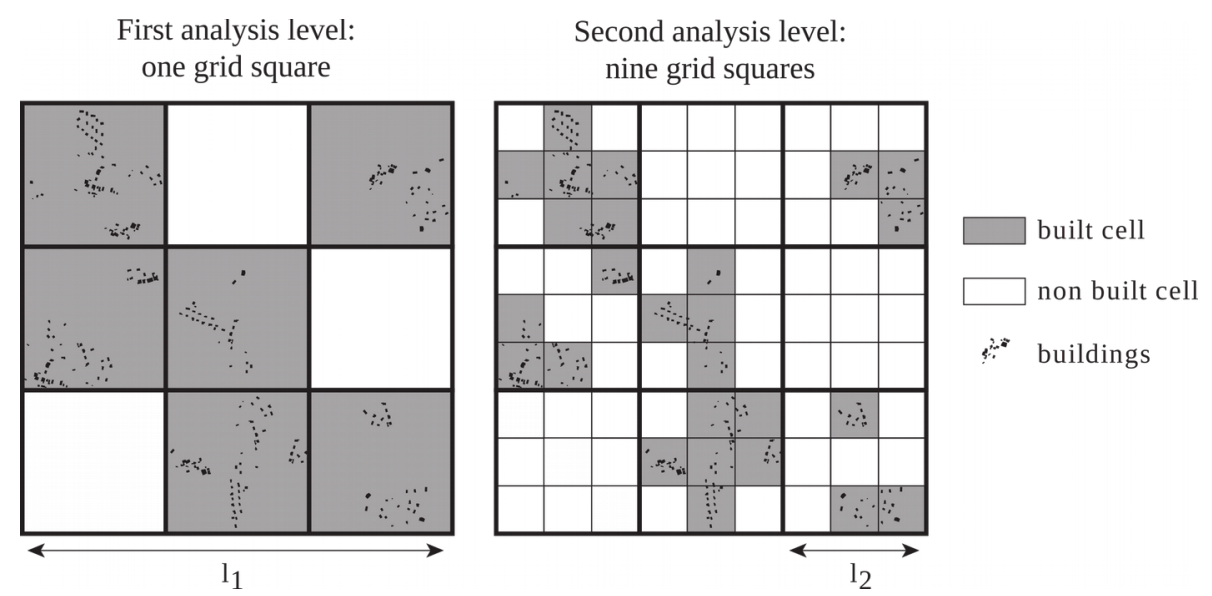

From a fractal point of view, two parameters determine the self-similarity dimension D of a pattern: the reduction factor $\mathrm{r}$ and the number of built elements $\mathrm{N}$ at each level of analysis (Mandelbrot, 1982).

$$
D=\frac{\log N}{\log r}
$$

Different values of fractal dimension can be used to differentiate built patterns with different topological properties: related, unrelated, or partially related across scales (De Keersmaecker et al., 2003). In MUP-City, the choice of a fractal dimension of the future built pattern is 
determined by the maximum number $\mathrm{N}_{\max }$ of cells that can be built per grid square and the reduction factor $\mathrm{r}$. For the current application, the reduction factor $\mathrm{r}$ is always equal to 3 . According to the fractal logic, if a grid square of size $l_{1}$ is not built, building is prohibited in the cells of size $l_{2}$ belonging to that grid square.

This multi-scale fractal modeling differs from the iterated function systems of Barnsley (1988) used for example by Milne (1991) to create fractal landscapes. It also differs from the midpoint displacement algorithm of Saupe (1988) adopted by Gardner (1999) for creating multi-scale maps in the software RULE.

Following the application of the fractal rule of urbanization, we know the number of cells in each grid square that can potentially be urbanized. The two planning rules are then used to select which cells to urbanize among the eligible cells. Multi-scale modeling implies that each planning rule is applied considering successively each level of analysis, i.e. each cell size. In the case of planning rule \#1, the calculation of the assessment criterion varies according to the size of cell considered (Table 1).

Table 1. Assessment values for the planning rule \#2 'proximity to existing roads'

\begin{tabular}{|c|c|c|c|c|c|}
\hline \multirow{2}{*}{ Distance to the closest road (number } & \multicolumn{5}{|c|}{ Size of cells (in m) } \\
\hline & $>500$ & {$[500-$} & [200-50[ & {$[50-20[$} & {$[20-0[$} \\
\hline & & 200[ & & & \\
\hline 0 & 1 & 1 & 1 & 1 & 1 \\
\hline 1 & 0 & 0.5 & 0.67 & 0.75 & 0.8 \\
\hline 2 & 0 & 0 & 0.33 & 0.5 & 0.6 \\
\hline 3 & 0 & 0 & 0 & 0.25 & 0.4 \\
\hline 4 & 0 & 0 & 0 & 0 & 0.2 \\
\hline 5 & 0 & 0 & 0 & 0 & 0 \\
\hline
\end{tabular}

Fifteen fractal scenarios have been simulated. $\mathrm{N}_{\max }$ varies from 3 to 7 , corresponding to a fractal dimension varying from 1 to 1.8. The form of the simulated patterns is typically fractal: neither dense nor dispersed (Fig. 3). This is coherent with a number of publications showing that urban growth engenders a fractal spatial organization (Batty and Xie, 1996; Benguigui et al., 2000). 
Scenarios that take into account planning rule \#1 generate more compact built patterns than the other fractal scenarios. Scenarios that take into account planning rule \#2 exhibit more elongated built forms.

\section{Nonfractal scenarios of residential development}

In creating nonfractal development scenarios, planning rules have been applied at a single scale corresponding to a grid of cells with sides $20 \mathrm{~m}$ long. The number of cells worth urbanizing was set a priori as the number of cells worth urbanizing identified by MUP-City for each of the fifteen corresponding fractal scenarios. Nonfractal simulated built patterns combine wisely compact and linear developments. Moderately compact developments are characterized by the presence of non built cells inside each built clusters. Less and smaller open spaces are preserved inside the built pattern than in the case of fractal scenarios. Linear extensions are in a straight line, in the case of planning rule \#1, or along existing roads, in the case of planning rule \#2 (Fig. 3). Real-world patterns of such forms are found for example in Belgium (Thomas et al., 2008) and in Italy (Camagni et al., 2002).

\section{Neutral scenarios of residential development}

Neutral landscape patterns are usually created starting from a blank or randomized initial situation (Gardner et al., 1987). Since they do not account for the effect of the initial situation, we created neutral landscape scenarios starting from the initial land use pattern (Hagen-Zanker and Lajoie, 2008). Five neutral nonfractal scenarios have been created by locating randomly new built-up cells. Neither the multi-scale fractal modeling nor the planning rules were applied. Five neutral fractal scenarios were created by applying the multi-scale fractal modeling but, instead of applying the planning rules, a simple random function allowed the location of the newly built-up cells. Neutral nonfractal scenarios generate purely dispersed built patterns. Neutral fractal scenarios generate the most dispersed among all the fractal built patterns (Fig. 3). 
Fig. 3. Types of residential development patterns generated by simulation - Focus on a 2052 ha zone located at the North-West of the city of Besançon. $N_{\max }$ is equal to 5 (14\% of the landscape is built-up)
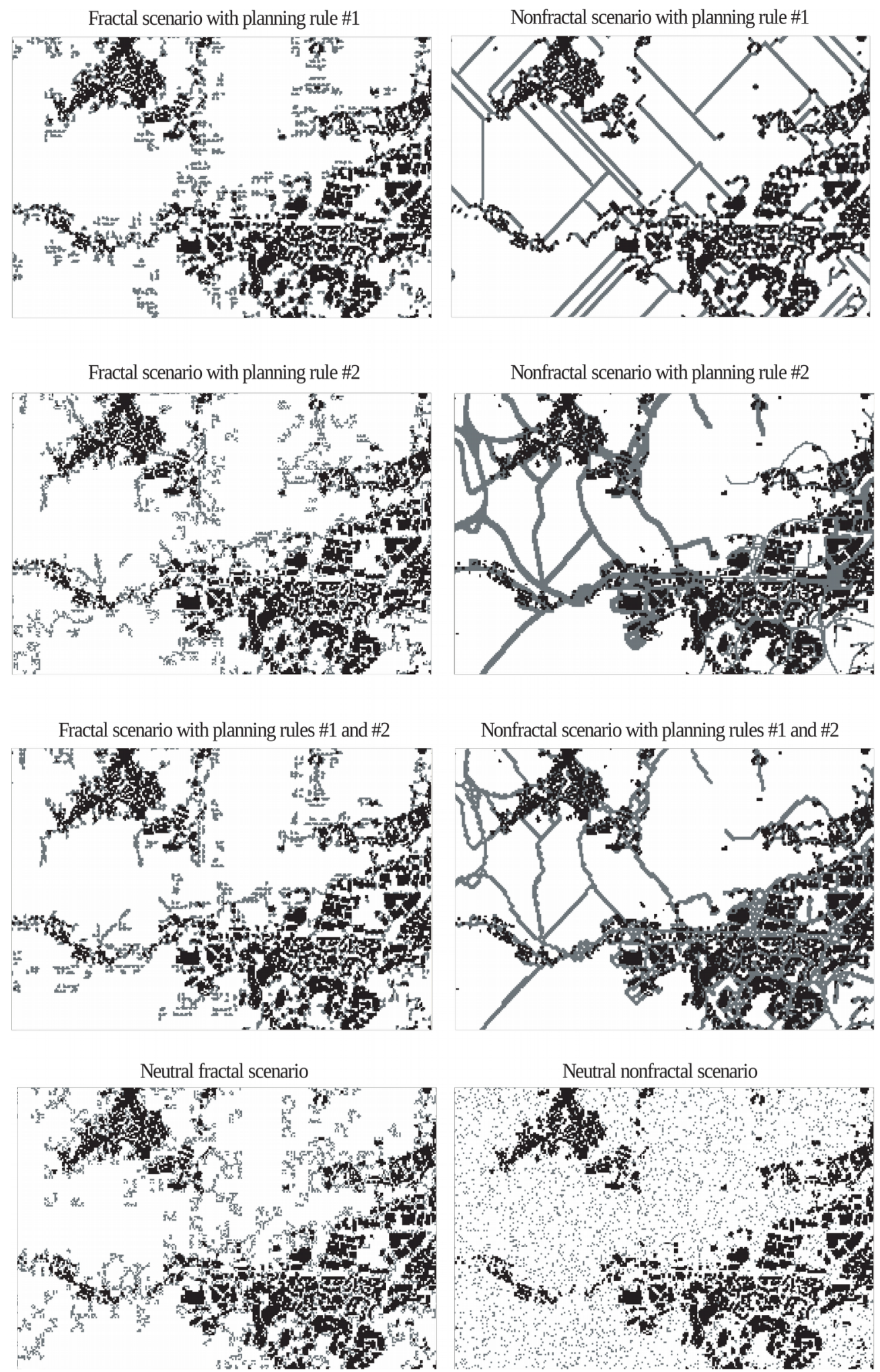


\section{Assessing change in habitat connectivity}

\subsection{Defining the landscape map}

Starting from the raster map of forest habitat, forest patches were identified using the Morphological Spatial Pattern Analysis (MSPA) available in the free software package GUIDOS (http://forest.jrc.ec.europa.eu/biodiversity/GUIDOS/). MSPA uses mathematical morphology to classify structural patterns on a binary map of land cover (Soille and Vogt, 2009; Vogt et al., 2007). The input map is composed of a foreground, which is the focal habitat (here the forest land cover), and a complementary background. The method applies a sequence of morphological operators (erosion, dilation and skeletonization) using a square-like structuring element. The size of this structuring element, ('edge width' in MSPA) was defined at two cells (40 m). Only the forest cells surrounded with at least $40 \mathrm{~m}$ of other forest cells have been considered as patch cores.

Seven classes of landscape elements are identified by MSPA (Soille and Vogt, 2009; Wickham et al., 2010): core, islet, bridge, loop, branch, edge, and perforation. MSPA classes have to be interpreted as classes of functional connectivity to create a structural map of potential connectivity (Vogt et al., 2009). In this perspective, forest surfaces were split into two classes: forest patches, resulting from the merging of MSPA classes 'core', 'perforation', and 'edge', and others forest surfaces favorable to animal movements defined as MSPA classes 'branch', 'bridge', 'loop', and 'islet'. The patches of size lower than 1 ha (containing only one 'core' cell surrounded by 'edge' cells) were reclassified as surfaces favorable to animal movements. This minimum patch size is somewhat small when comparing with other studies: 5 ha in Minor and Urban (2007), 10 ha in Vogt et al. (2009); 25 ha in Vogt et al. (2007); however it seems to be relevant regarding both the fine-grained data used and the generic function associated with the habitat patches.

When overlaying the forest habitat map with a scenario map of residential development, a synthetic landscape map is obtained that includes the simulated built pattern and the remaining forest pattern. To compare the landscape maps, we followed the three principles set by Gardner (1999): map grain and extent must be the same; maps must be of sufficient size so that boundary 
effects are minimized; comparisons must account for differences in the proportion of the landscape covered by habitat, designated by p below (Gardner et al., 1987).

\subsection{Patch-based graphs of landscape connectivity}

Each landscape map was used as an input data layer in a graph-based modeling of connectivity. Graphs were built by using forest patches as nodes having a two-dimensional geometry (Galpern et al., 2011), and by computing edge-to-edge least-cost distances between all pair of patches to define the links. Least-cost distances were calculated using resistance values assigned to each land cover class:

- habitat patch: 1

- forest surface favorable to movement: 1

- built surface: 10

- background: 5

Since our approach is generic, the resistance values were defined by assuming that built surfaces involve the higher resistance to individual movement, and that background (other surfaces excepted forest) plays an intermediary role.

The scenarios were compared by assessing the global connectivity while ignoring the local variability. The analysis was based on the complete graph, containing all the information about the potential paths between the nodes (Galpern et al., 2011). Many metrics can be applied to estimate connectivity at the entire graph level. Direct metrics are more relevant when dealing with change in habitat connectivity since they take into account the graph structure. Among all existing direct metrics, we chose the probability of connectivity (PC) index proposed by Saura and Pascual-Hortal (2007). The PC index measures the probability that an animal remains in the same set of connected patches when moving:

$$
P C=\frac{\sum_{i=1}^{n} \sum_{\substack{j=1 \\ j \neq i}}^{n} a_{i} a_{j} p_{i j}^{i}}{A^{2}}
$$

where $n$ is the total number of patches, $a_{i}$ and $a_{j}$ are the areas of the patches $i$ and $j$, $p_{i j}{ }^{*}$ is the maximal probability of the potential paths between $\mathrm{i}$ and $\mathrm{j}$, and $\mathrm{A}$ is the total area under study. $\mathrm{p}_{\mathrm{ij}}$ can be computed with an exponential function so that : 


$$
p_{i j}=e^{-k d_{i j}}
$$

where $d_{i j}$ is the least cost distance between $i$ and $j$, and $k(0<k<1)$ expresses the strength of the decrease of the dispersal probabilities resulting from this exponential function. As we analyze a generic forest habitat, the PC index was computed using increasing values of $\mathrm{k}$ for $\mathrm{p}=0.05$, corresponding to increasing maximum dispersal distances. To draw the curves, we calculated the square root of the PC (sqrPC), which represents the ratio between the reachable habitat area and the total area of the study zone. The PC values were also compared to those obtained from the initial landscape map, allowing us to measure the relative loss of connectivity involved with each scenario (Saura and Rubio, 2010).

\section{Results}

\section{Analysis of the MSPA maps}

We obtained five series of eight synthetic maps exhibiting the same proportion p of the landscape covered by forest habitat. Table 2 shows a strong increase of the number of new built-up cells with an increasing value of $\mathrm{N}_{\max }$. The proportion of forest is initially high (43\%) and remains quite high (at least 30\%) even for the scenarios characterizing by the highest amount of built area. Although Gardner and Urban (2007) have suggested to focus inferential studies on landscapes with low values of p because the maximum number of patches in random landscapes occurs at $\mathrm{p}^{\sim}$ 0.3, Riitters et al. (2009) showed clear and large differences between foreground patterns on maps with large p when studying landscape patterns created with MSPA.

Table 2. Percentage of land cover classes calculated for each series of scenarios.

Forest (p) Built initially Built simulated Total built Background

$\begin{array}{llllll}\text { Initial landscape } & 0.43 & 0.05 & 0.00 & 0.05 & 0.52 \\ \text { Simulated landscapes } & & & & & \\ \text { Nmax }=3 & 0.42 & 0.05 & 0.01 & 0.07 & 0.51 \\ \text { Nmax }=4 & 0.41 & 0.05 & 0.04 & 0.09 & 0.50 \\ \text { Nmax }=5 & 0.40 & 0.05 & 0.09 & 0.14 & 0.47 \\ \text { Nmax }=6 & 0.36 & 0.05 & 0.17 & 0.22 & 0.42 \\ \text { Nmax }=7 & 0.30 & 0.05 & 0.31 & 0.37 & 0.33\end{array}$


Considering scenarios characterized by the same p value, only the form of the forest pattern varies. This variation results from differences in the form of the simulated residential development. Table 3 shows that residential development affects both the mean patch size and the maximum patch size. Those two indexes decrease when the built area increases. The number of patches increases in the case of fractal scenarios. In the case of nonfractal scenarios, however, this number decreases since the built area represents $22 \%$ of the total area. The number of patches is even lower than for the initial map in the case of nonfractal scenario with planning rule \#1 when the built area is the highest (37\% of the study area). In general, the higher the intensity of residential growth, the higher the differences between the scenarios.

Table 3 shows that the impact of patterns of residential developments on the form of the remaining forest pattern clearly differs between fractal and nonfractal scenarios. In the case of fractal scenarios, the increase in the number of patches is proportional to the strength of the residential development. This is not the case for nonfractal scenarios. The percentage of forest zones favorable to movements increases as a consequence of residential growth in the case of fractal scenarios whereas it does not increase and even decreases in the case of nonfractal scenarios. The percentage of forest habitat decreases quickly in the case of fractal scenarios whereas it decreases only when the built area reaches $14 \%$ of the total area in the case of nonfractal scenarios. The two planning rules have a much stronger influence on the form of the remaining forest pattern with nonfractal scenarios than with fractal scenarios. Considering the neutral scenarios, fewer differences are observed between fractal neutral scenarios and other fractal scenarios than between nonfractal neutral scenarios and other nonfractal scenarios. Neutral nonfractal scenarios exhibit a residential development full of holes and the remaining forest patches are very small. They are numerous when the residential development is weak; they are very sparse, even absent, when the residential development is intense.

Only three fractal scenarios are characterized by better values of basic indexes than the nonfractal scenarios of the same series (Table 3). Here, we consider that a scenario is better when it is nearer to the initial situation. When the built area represents $14 \%$ of the total study area, the fractal scenario with planning rule \#2 has the highest maximum patch size; the fractal scenario with both planning rules has the lowest number of patches. When the built area represents $0.09 \%$ of the total study area, the fractal scenario with planning rule \#2 has the highest maximum patch size. 
Table 3. Basic spatial indexes calculated for each series of scenarios.

\begin{tabular}{|c|c|c|c|c|c|c|c|c|c|c|c|}
\hline \multirow{3}{*}{$\begin{array}{l}\text { Built } \\
\text { area (\%) } \\
0.05\end{array}$} & \multirow{3}{*}{\begin{tabular}{|l|} 
Scenario \\
Initial land use \\
\end{tabular}} & \multicolumn{2}{|c|}{$\begin{array}{l}\text { Number of } \\
\text { forest patches }\end{array}$} & \multicolumn{2}{|c|}{$\begin{array}{l}\text { Mean patch size } \\
\text { (in ha) }\end{array}$} & \multicolumn{2}{|c|}{$\begin{array}{l}\text { Maximum patch size } \\
\text { (in ha) }\end{array}$} & \multirow{2}{*}{\multicolumn{2}{|c|}{$\begin{array}{r}\begin{array}{r}\text { Forest area favorable to } \\
\text { animal movements (\%) }\end{array} \\
0.08\end{array}$}} & \multicolumn{2}{|c|}{$\begin{array}{c}\text { Habitat area } \\
(\%)\end{array}$} \\
\hline & & \multirow{2}{*}{\begin{tabular}{r|}
700 \\
non fractal
\end{tabular}} & \multirow{2}{*}{ fractal } & \multirow{2}{*}{$\begin{array}{r}57.3 \\
\text { non fractal }\end{array}$} & \multirow{2}{*}{ fractal } & \multirow{2}{*}{\begin{tabular}{|r|}
2742 \\
non fractal
\end{tabular}} & \multirow[b]{2}{*}{ fractal } & & & & 0.35 \\
\hline & & & & & & & & non fractal & fractal & non fractal & fractal \\
\hline \multirow[t]{4}{*}{0.07} & Planning rule \#1 & 786 & 722 & 50.7 & 53.5 & 2272 & 2097 & 0.08 & 0.09 & 0.35 & 0.34 \\
\hline & Planning rule \#2 & 729 & 724 & 54.8 & 53.8 & 2741 & 2707 & 0.08 & 0.09 & 0.35 & 0.34 \\
\hline & Both planning rules & 704 & 731 & 56.9 & 53.7 & 2742 & 2720 & 0.08 & 0.08 & 0.35 & 0.34 \\
\hline & Neutral & 961 & 732 & 32.4 & 51.1 & 2072 & 2640 & 0.15 & 0.10 & 0.27 & 0.33 \\
\hline \multirow[t]{4}{*}{0.09} & Planning rule \#1 & 865 & 785 & 45.9 & 46.6 & 2030 & 1992 & 0.08 & 0.10 & 0.35 & 0.32 \\
\hline & Planning rule \#2 & 833 & 777 & 46.8 & 48.2 & 1984 & 2602 & 0.08 & 0.09 & 0.34 & 0.33 \\
\hline & Both planning rules & 771 & 784 & 51.6 & 48.4 & 2267 & 2167 & 0.08 & 0.09 & 0.35 & 0.33 \\
\hline & Neutral & 2361 & 819 & 6.8 & 41.7 & 175 & 2362 & 0.26 & 0.12 & 0.15 & 0.30 \\
\hline \multirow[t]{4}{*}{0.14} & Planning rule \#1 & 857 & 859 & 45.1 & 38.2 & 2026 & 1859 & 0.07 & 0.11 & 0.34 & 0.29 \\
\hline & Planning rule \#2 & 1179 & 878 & 30.6 & 39.3 & 1316 & 2393 & 0.08 & 0.10 & 0.31 & 0.30 \\
\hline & Both planning rules & 866 & 837 & 44.7 & 42.2 & 2010 & 1969 & 0.07 & 0.09 & 0.34 & 0.31 \\
\hline & Neutral & 1184 & 1006 & 1.8 & 29.6 & 8 & 1344 & 0.35 & 0.14 & 0.04 & 0.26 \\
\hline \multirow[t]{4}{*}{0.22} & Planning rule \#1 & 809 & 980 & 45.6 & 28.5 & 1962 & 1498 & 0.06 & 0.12 & 0.32 & 0.24 \\
\hline & Planning rule \#2 & 1538 & 1077 & 20.3 & 27.8 & 470 & 1404 & 0.09 & 0.11 & 0.27 & 0.26 \\
\hline & Both planning rules & 806 & 1002 & 45.8 & 31.2 & 1964 & 1576 & 0.06 & 0.10 & 0.32 & 0.27 \\
\hline & Neutral & 11 & 1250 & 1.2 & 19.9 & 2 & 937 & 0.35 & 0.14 & 0.00 & 0.22 \\
\hline \multirow[t]{4}{*}{0.37} & Planning rule \#1 & 698 & 1254 & 47.1 & 17.7 & 1109 & 858 & 0.05 & 0.12 & 0.29 & 0.19 \\
\hline & Planning rule \#2 & 1369 & 1229 & 16.3 & 18.2 & 470 & 971 & 0.11 & 0.11 & 0.19 & 0.19 \\
\hline & Both planning rules & 828 & 1279 & 39.5 & 18.7 & 1640 & 966 & 0.05 & 0.10 & 0.28 & 0.21 \\
\hline & Neutral & 0 & 1549 & 0.0 & 12.9 & 0 & 839 & 0.29 & 0.13 & 0.00 & 0.17 \\
\hline
\end{tabular}

In bold print: better value of some indexes considering each series of scenarios of the same p

Fig. 4 to 6 display three examples of the maps obtained. The initial landscape shows local variations in the form of the forest habitat. In the North, forest zones favorable to animal movements are mainly located in the background. In the South-West, habitat patches and zones favorable to animal movements are inter-penetrating. In the East of the study area, patches of background exist inside the large habitat patches. Simulated residential development essentially concentrates on background cells of the initial landscape. A fractal residential development creates new background cells surrounded by forest zones favorable to movements inside habitat patches (Fig. 5). A nonfractal residential development creates ribbons-like background or built cells corresponding to the roads along which is concentrated the residential development. The ribbons are not surrounded by forest zones favorable to animal movements (Fig. 6). Figs. 5 and 6 nicely illustrate the crucial difference between fractal and nonfractal urban patterns: a clear-cut limit between built and non built patterns characterizes nonfractal urban forms; a fuzzy limit marked by the development of zones favorable to animal movements characterizes fractal urban forms. 
Fig. 4. Initial landscape. The built area represents $5 \%$ of the total area.

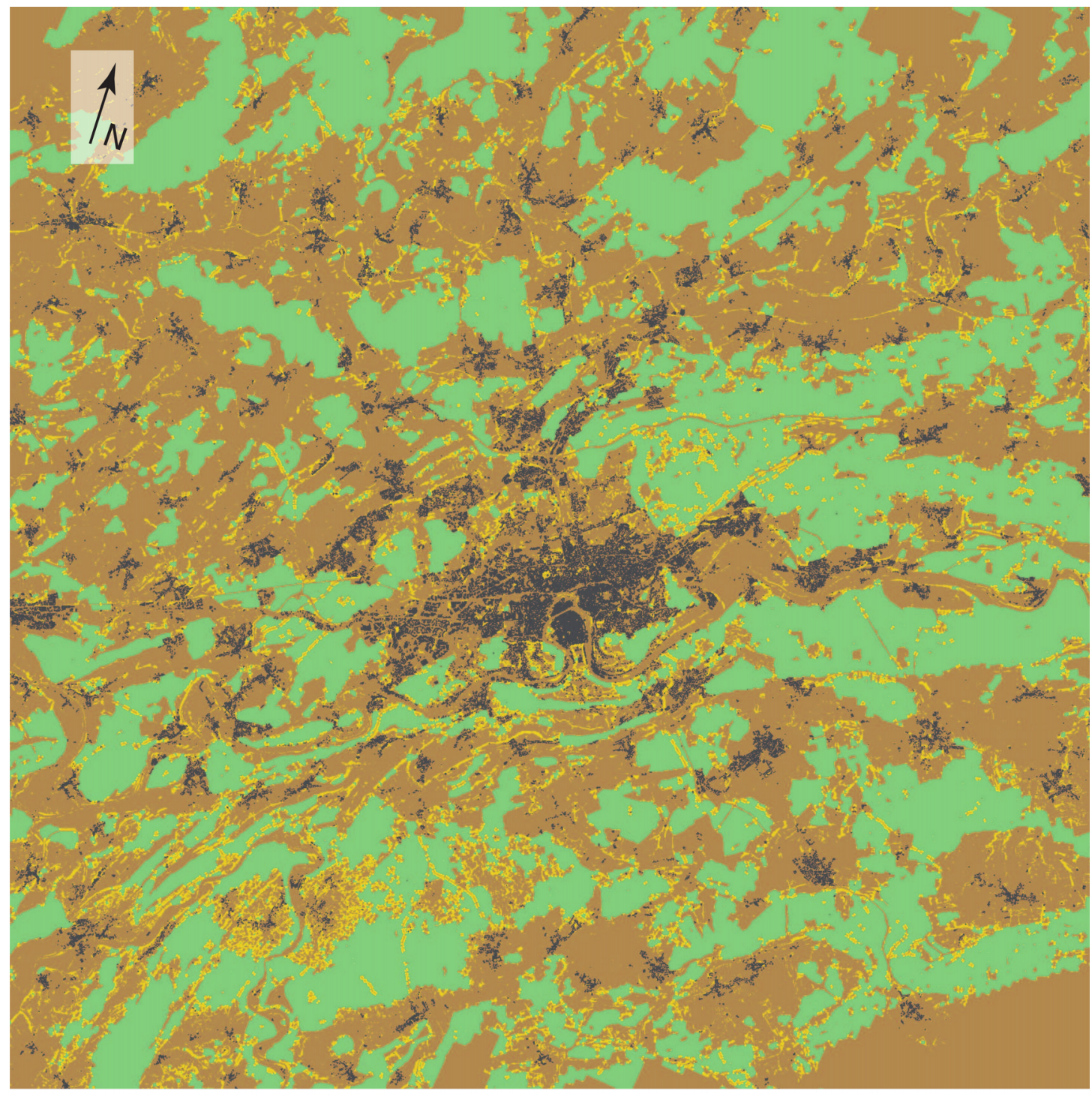

built surface

forest patch

background

forest zone favorable to animal movements 
Fig. 5. Simulated landscape resulting from a fractal residential development constrained by two planning rules. The built area represents $14 \%$ of the total area.

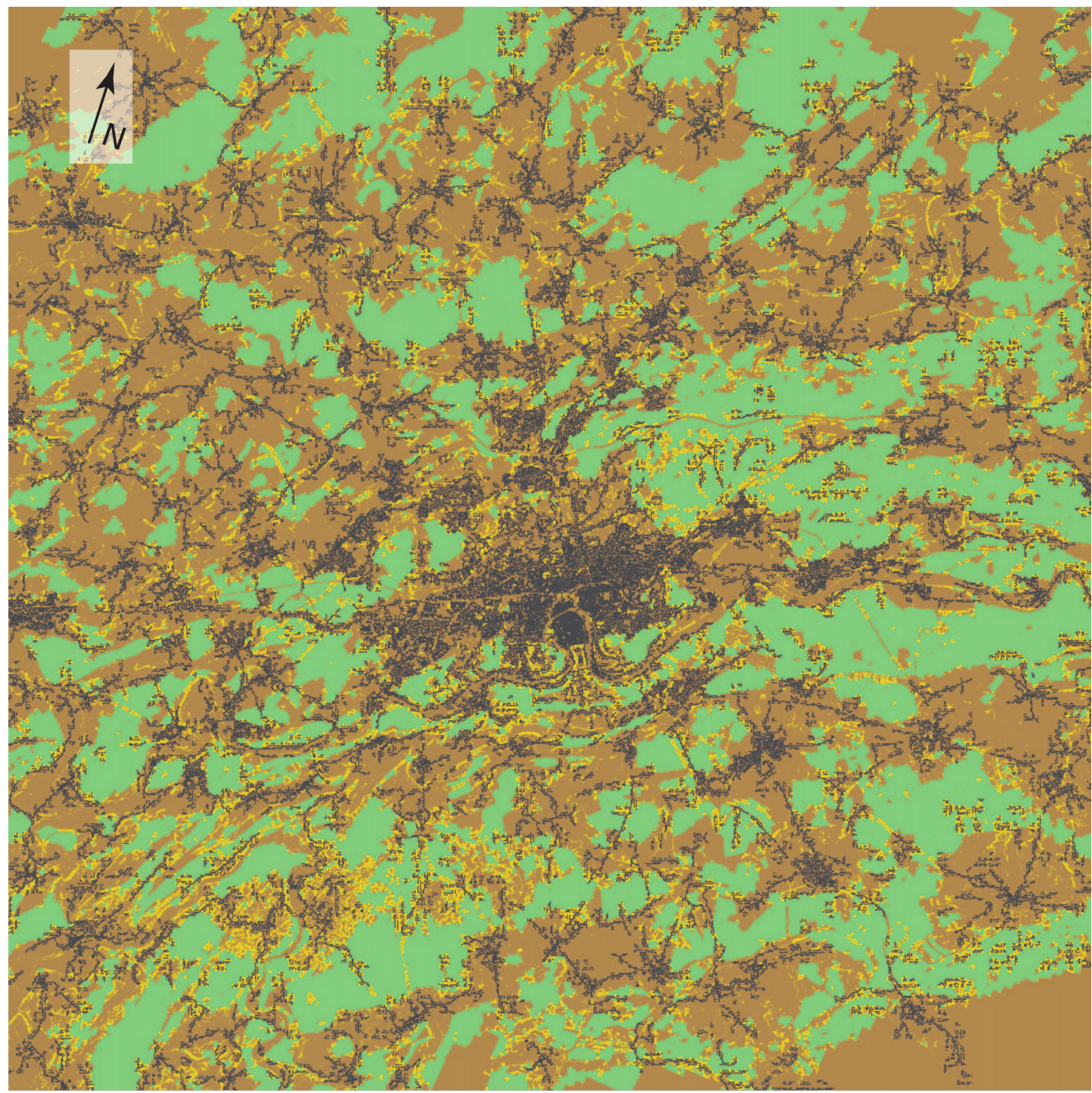

built surface

forest patch

background

forest zone favorable to animal movements 
Fig. 6. Simulated landscape resulting from a nonfractal residential development constrained by two planning rules. The built area represents $14 \%$ of the total area

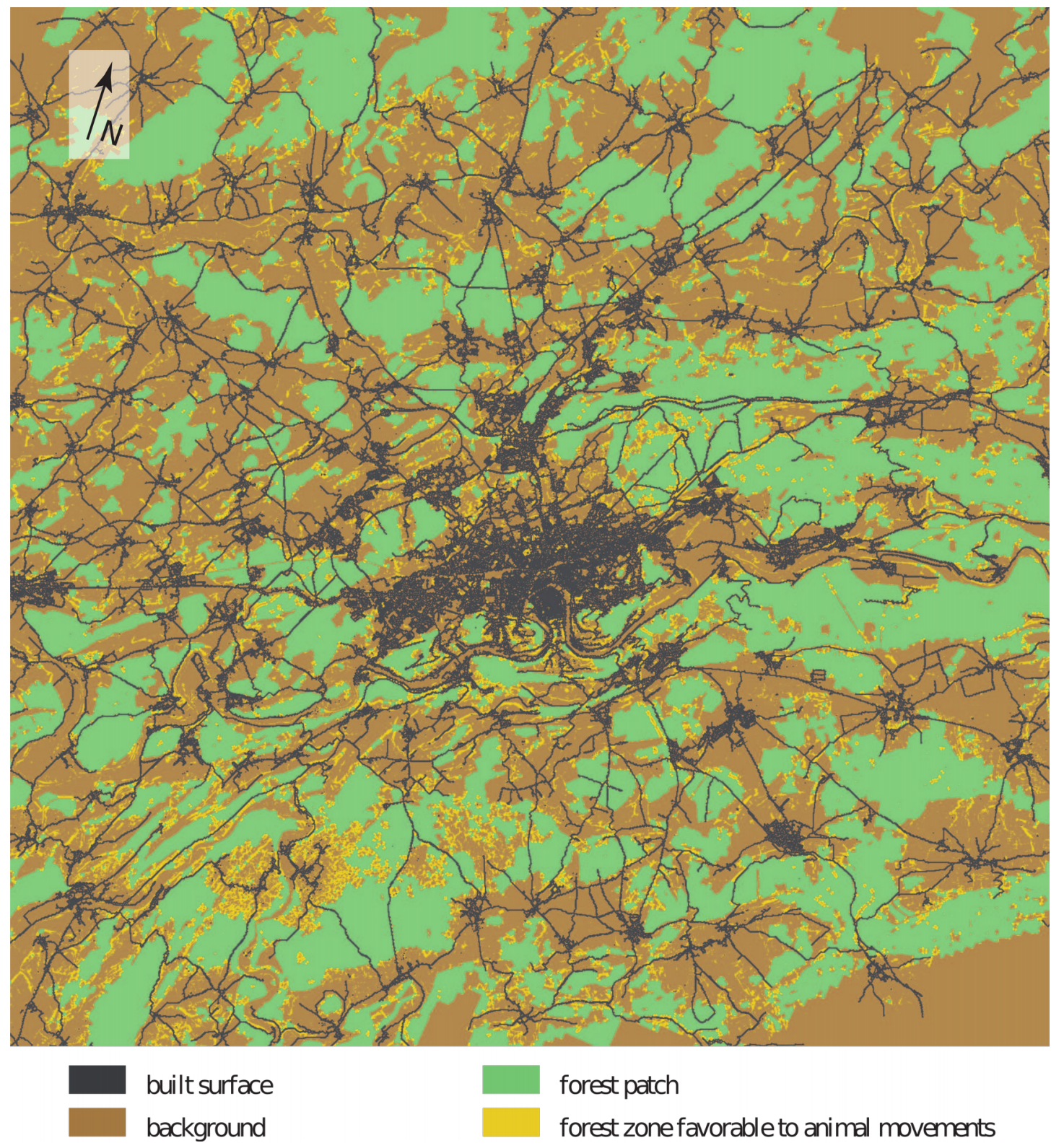

\section{Assessing the loss of connectivity of animal habitat}

The complete graphs that model the forty landscape maps count a maximum of 2361 nodes (2 785980 links). Fig. 7 displays the square root of the PC index (sqrPC) for each series of scenarios. It shows that the forest connectivity decreases as the number of built cells increases. The maximal value of the sqrPC is 0.33 when the fraction of built cells is $0.07 \%$, and 0.26 when the fraction of built cells reaches $0.37 \%$. This decrease of the sqrPC varies according to the 
scenarios. In general, the PC index decreases more rapidly than the fraction of forest. This reveals a clear influence of the form of the residential development on the habitat connectivity.

\section{Fig. 7. sqrPC values for each series of scenarios}
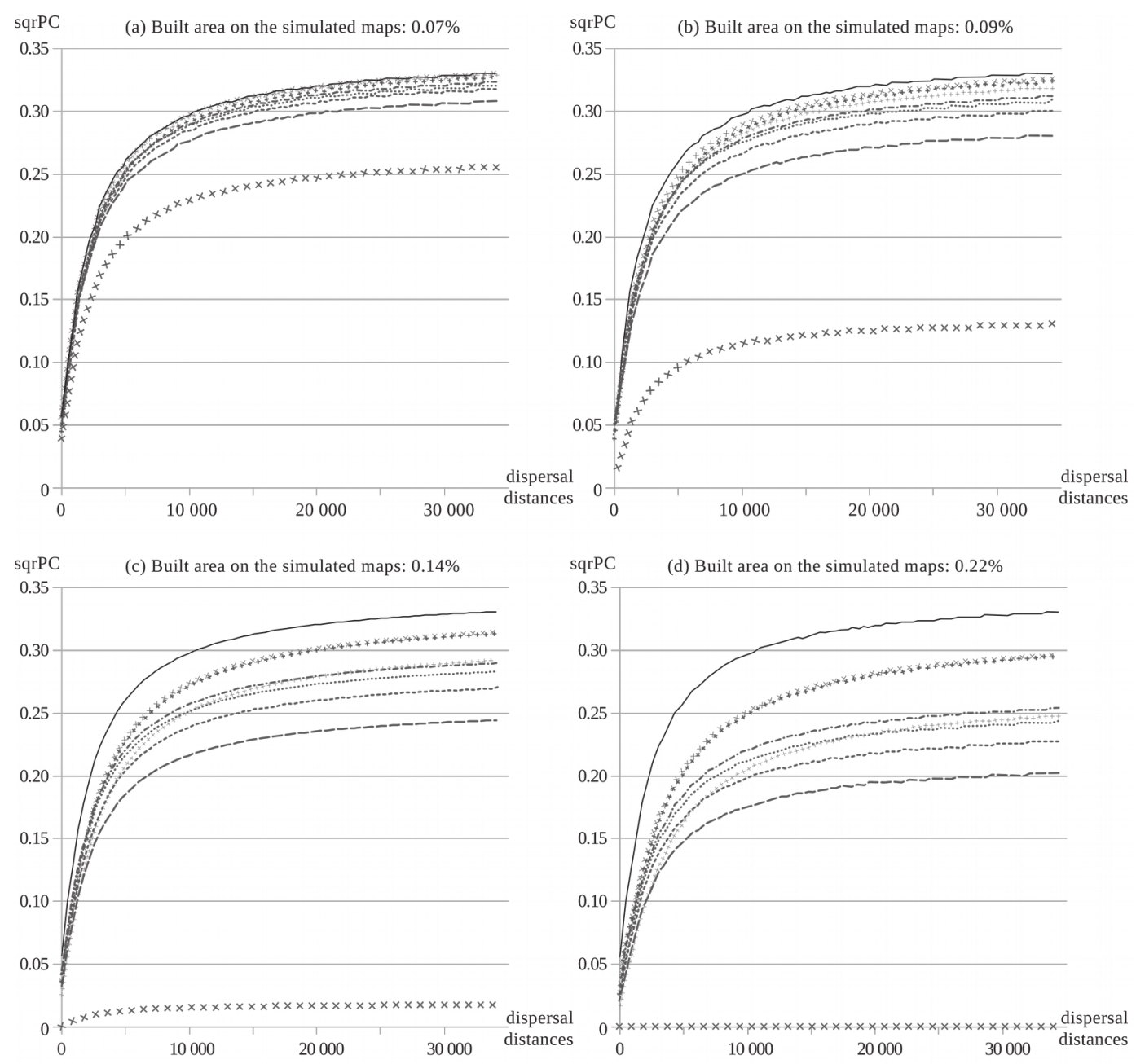

sqrPC (d) Built area on the simulated maps: $0.22 \%$
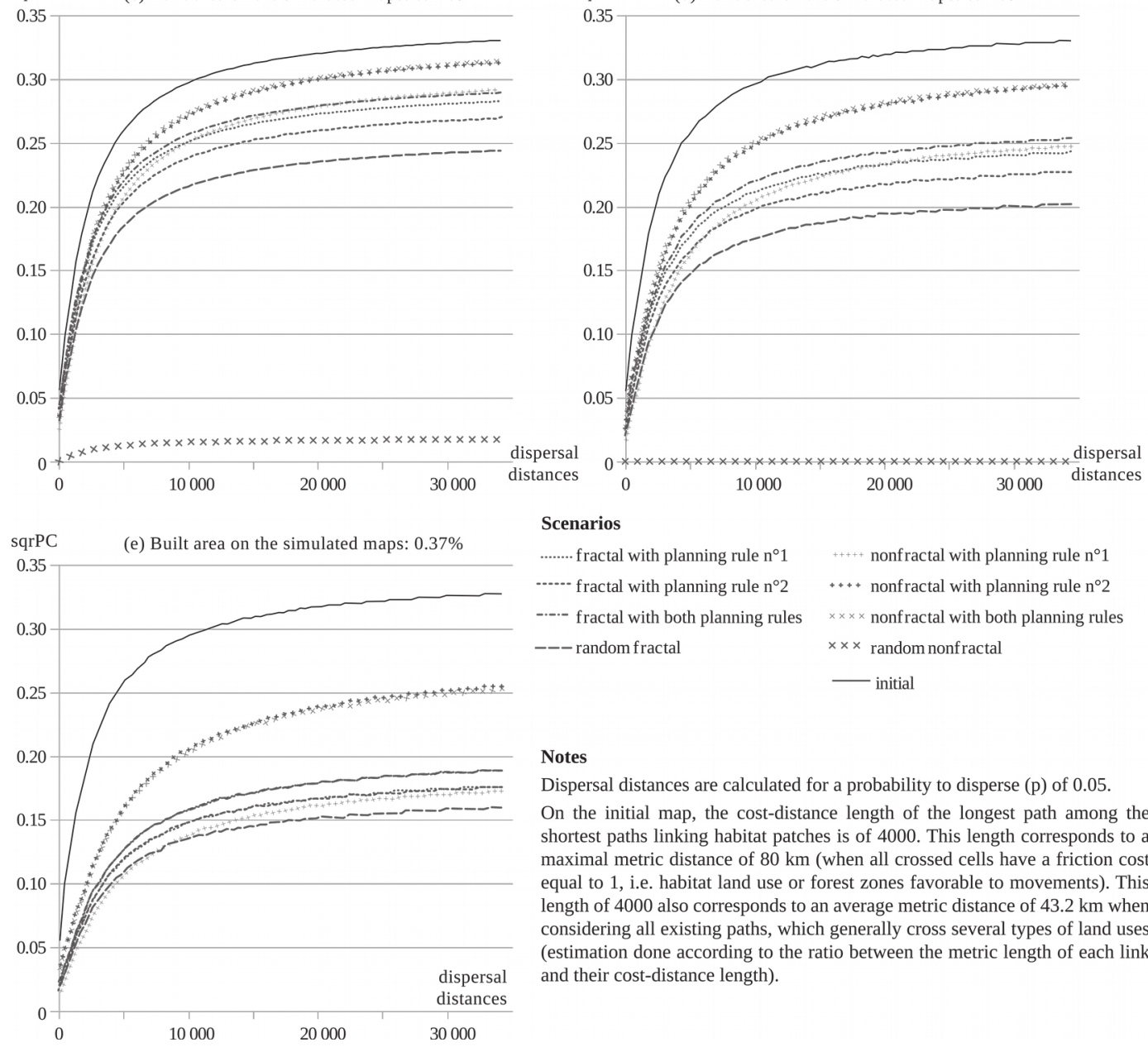

Scenarios

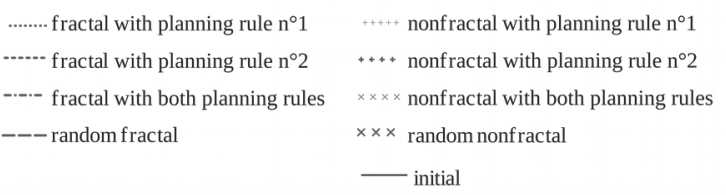

Notes

Dispersal distances are calculated for a probability to disperse (p) of 0.05 .

On the initial map, the cost-distance length of the longest path among the shortest paths linking habitat patches is of 4000 . This length corresponds to a maximal metric distance of $80 \mathrm{~km}$ (when all crossed cells have a friction cost equal to 1 , i.e. habitat land use or forest zones favorable to movements). This length of 4000 also corresponds to an average metric distance of $43.2 \mathrm{~km}$ when considering all existing paths, which generally cross several types of land uses (estimation done according to the ratio between the metric length of each link and their cost-distance length). 
Fig. 8. Change rate of the PC index considering low dispersal distances
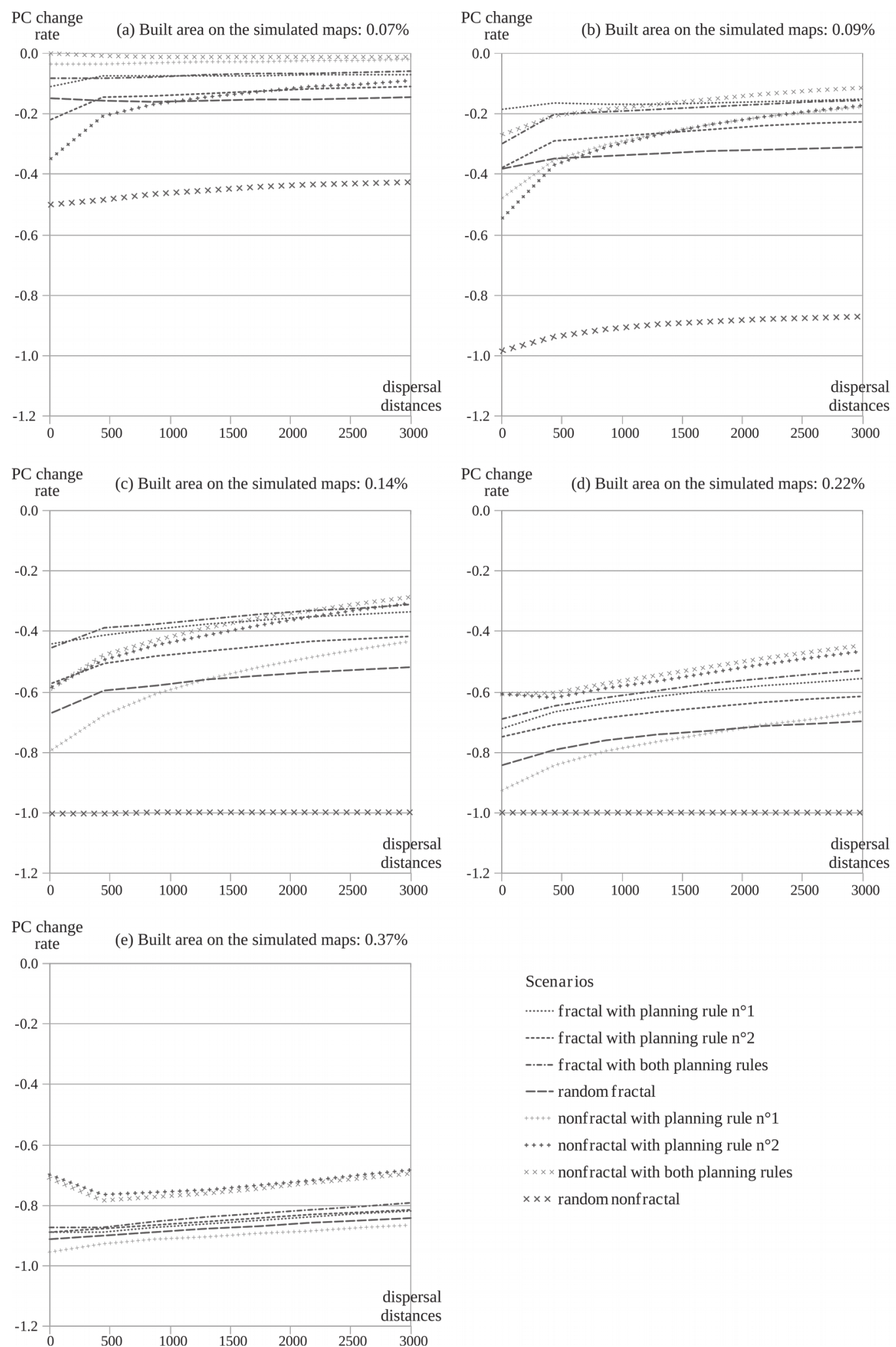
Scenarios
....... fractal with planning rule $n^{\circ} 1$
...-.. fractal with planning rule $n^{\circ} 2$
-..-- fractal with both planning rules
--- random fractal
${ }^{+++++}$nonf ractal with planning rule $\mathbf{n}^{\circ} 1$
${ }^{++++}$nonfractal with planning rule $n^{\circ} 2$
$x \times x \times$ nonf ractal with both planning rules
$\times \times \times$ random nonfractal 
Nonfractal scenarios with planning rule \#2, with or without rule 1, obtain the best sqrPC value, and their curves are very close. Fig. 7 shows, however, weak differences of sqrPC values between fractal and nonfractal scenarios when the intensity of urbanization is low (from $0.07 \%$ to $0.09 \%$ of built cells in the landscape). In the case of nonfractal scenarios, the connectivity of scenarios with planning rule \#2, combined or not with the rule \#1, is better than the connectivity of scenarios not taking into account this rule. Conversely, in the case of fractal scenarios, the connectivity of scenarios with planning rule \#1, combined or not with rule \#2, is better than the connectivity of scenarios not taking into account this rule. The neutral random scenarios exhibit a low level of connectivity, especially the nonfractal random scenarios.

Considering the same intensity of urbanization, the ranking of the scenarios may vary according to the maximal dispersal distance considered. When the intensity of urbanization is low or quite low (from $0.09 \%$ to $0.14 \%$ of built cells in the landscape) and considering low dispersal distances, fractal scenarios have a better PC index than nonfractal scenarios (Fig. 8). However, the PC index of nonfractal scenarios increases dramatically for long dispersal distances and finally exceeds the PC index of fractal scenarios. When the number of built cells is the highest (between $0.22 \%$ and $0.37 \%$ of built cells in the landscape) fractal scenarios never have a better PC index than nonfractal scenarios whatever the dispersal distance considered.

\section{Discussion and perspectives}

\section{Reliability and interest of the methodology for urban planning and design}

We have proposed a simple and repeatable methodology which requires a low amount of data and parameters:

- Creation of residential development scenarios using the software MUP-City

- Use of the MSPA method for identifying habitat patches

- Calculation of basic spatial indexes of habitat fragmentation

- Calculation of the PC index for assessing the global habitat connectivity

We have systematically explored the effect of two urban models, two planning rules, and a varying intensity of urbanization on some structural and functional aspects of ecological habitat. Simulated scenarios of residential development are theoretical, more or less compact and linear, 
fractal or nonfractal. In order to identify general rules for landscape planning and design, we have created forty scenarios of residential development that allow us to simulate and analyze a progressive decrease of the amount of ecological habitat in the landscape, responding to the requirement of a generalized gradient of habitat pattern in view of an explanatory theory (Gardner, 1999). Apart from the neutral scenarios, the simulated scenarios represent stylized facts which try to mimic observed phenomena. They are not realistic because they do not take into account environmental constraints (slopes, soils...) nor planning laws or regulations, not even household behaviors. But they allow testing the impacts of variables determining a built form on the surrounding forest patterns. The simulated landscapes can be used to create a general framework for which real landscapes can be compared (Malanson, 2002). We concentrate on one aspect which determines species survival in a context of urban sprawl - i.e. connectivity between patches - to give new insights on the transformation of this single ecological condition as a result of urban development process.

The urban modeling used for creating residential development scenarios clearly differs from a cellular automata modeling: it is morphologically explicit but not predictive. Modeling stylized facts allowed us to create forty scenarios of residential development whereas cellular automata applications allowed the creation of only few scenarios: for instance two in Mitsova et al (2011), three in Syphard et al. (2005) and Aguilera et al. (2011), five in Herold et al. (2005). The comparison of ecological habitat patterns resulting from simulated scenarios of urban growth is most often based on landscape metrics potentially associated with connectivity indexes (Mitsova et al., 2011). We chose the same indexes for comparing our simulated scenarios. However, we went deeper into the assessment of habitat connectivity by considering a wide range of dispersal distances. This allowed us to measure a general mobility potential for a range of animal species by analyzing a generic ecological habitat, knowing that the effective mobility of each of the considered species is different.

In general, habitat connectivity seems to be better preserved in the case of nonfractal scenarios of residential development than fractal scenarios. However, for species characterized by low dispersal distances, some fractal scenarios may be more favorable to their mobility. Regarding these results, our study confirms that the relationship between urban form and ecological 
processes is equivocal. It seems impossible to identify a single threshold or a unique rule for residential development allowing to preserve all species living in a landscape (With and Crist, 1995). When the intensity of urbanization is low, we observe weak differences of habitat connectivity between fractal and nonfractal scenarios. In these cases, a fractal residential development may be as interesting as a wisely compact development.

The fragmentation effect of the road network is taken into account through the decrease of patch area and the isolation of resource patches. The road network is indirectly taken into account through planning rule \#2 which favors residential development close to an existing road. No friction value has been assigned to the roads in the calculation of least-cost distances between patches. As in Mitsova et al. (2010) and Aguilera et al. (2010), scenarios have been based on the actual road network, but its extension with relation to the residential development was not simulated. Many other variables than those taken into account in our research influence the way roads affect the environment, in particular road width, equipment (i.e. fences), and volume of traffic (Coffin, 2007; Forman and Alexander, 1998). Moreover, the barrier effect of roads may be stronger for some species than others (Minor and Lookingbill, 2010). The ecological role of the road network varies in recent studies in the field: Vasas et al. (2009) have considered roads as absolute barriers for forest carabid species; Fall et al. (2007) have based the friction value of roads on expert opinion concerning their effect on woodland caribou; Zetterberg et al. (2010) have assigned roads to a class with friction value only related to energy expenditure, rather than mortality risk. These recent works support the hypothesis that the effect of road is speciesspecific.

\section{Going deeper into the assessment of landscape connectivity}

We have defined the habitat patches following a morphological preprocessing applied to the focal habitat class (forest surfaces), using MSPA. This preprocessing is justified by the assumption that a core zone is required to define habitat patches in a relevant manner, the edge part of a patch being subjected to several disturbances such as predation or anthropic activities. This assumption is probably not valid in the case of some species which are less sensitive to these disturbances, but the assumption seems to be justified in the context of our generic 
approach. Nevertheless, two critical points have to be outlined with the use of MSPA. The first point concerns the 'edge width' parameter of MSPA, which defines the size of the structural element used in the erosion/dilation process to distinguish the core class from all other classes. The 'edge width' plays a strong role in the definition of habitat patches as well as on the derived connectivity measurements. This point has already been discussed in Ostapowicz et al. (2008), Riitters et al. (2007), Vogt et al. (2007). In comparison with the edge width of $40 \mathrm{~m}$ used in the present study, Vogt et al. (2009) chose an edge width of $75 \mathrm{~m}$, arguing that this value is typical for a wide range of species. However it appears difficult to represent the relationships between species and the disturbances they perceive from the matrix by a unique value of edge width. In this respect, our choice for a width of $40 \mathrm{~m}$ may restrict the generic value of the results. As suggested in Vogt et al. (2009), it would be useful to perform a multi-scale sensitivity study, with the help of expert species knowledge, to identify species-specific scales for which it would be possible to set an appropriate edge width.

The second critical point regarding the use of MSPA concerns the merging of the seven morphological classes. In our study, the habitat patches resulted from the merging of 'core', ‘edge’ and ‘perforation’ classes, as in Vogt et al. (2009) and Soille and Vogt (2009). All the other MSPA classes were considered as zones favorable to movement, which somewhat differs from previous works where the class "islet" was removed and where only the class "loop" has contributed to the connector features. As these classifications induce differences in the computed least-cost distances, the resistance values or cost assigned to each class needs further consideration. This question of cost values may indeed contribute to increase the part of error in a graph model (Rayfield et al., 2010; Spear et al., 2010). Field observations could be used as guideline to define the costs (Belisle, 2005) but this method often raises practical problems and cannot by applied in a generic approach. A solution could be to take into account multiple leastcost pathways as suggested in Rayfield et al. (2010).

The scenarios of residential development have been compared considering a global assessment of forest patches connectivity. The PC index was used because of the ability to include several basic aspects of ecological connectivity (distances between patches, dispersal distance, and patch areas) while having numerous expected properties favoring a high level of connectivity (Saura 
and Pascual-Hortal, 2007). In the present study, the choice for the PC index is consistent with the use of a complete graph. However, one could argue that the comparison done here remains at a global level, giving no access to more precise aspects of connectivity. To complete the analysis,

several courses may be investigated. One possibility could be to focus on the spatial impact of the loss of connectivity induced by residential development. By applying locally the PC index as a 'delta parameter' (Saura and Pascual-Hortal, 2007; Urban and Keitt, 2001), it would be possible to determine the places where a given scenario of residential development could have a stronger effect on the global connectivity. Another possibility would be to distinguish aspects of the connectivity which refer only to the loss of patch areas (PC intra) from aspects that refer to the loss of potential dispersal flux (PC flux) or the loss of potential crossing (PC connector) (Saura and Rubio, 2010).

Fractal scenarios sometimes show a better connectivity than nonfractal scenarios when the dispersal distances are low whereas the inverse phenomenon occurs for high dispersal distances. This observation may support the hypothesis that a fractal urban form allows local animal movements from one patch to another, but does not facilitate the crossing of the entire landscape. Conversely, the existence of continuous ribbons of buildings along the roads in the case of nonfractal scenarios creates a partitioning of the forest pattern. As a result we may hypothesize a strong barrier effect of roads that could be highlighted by other connectivity measures than the only PC index.

\section{Conclusion}

In this paper, we have explored the relationship between urban forms and ecological processes. We have shown that fractal scenarios of residential development are almost equivalent to wisely compact scenarios regarding the connectivity of forest habitat when the residential development is weak. In the case of more intense residential development, nonfractal scenarios are better than fractal scenarios except when considering low dispersal distances. The effect of two planning rules on the landscape connectivity varies with the form of the simulated residential development. The planning rule \#2 'Proximity to existing roads' improves the landscape connectivity of fractal scenarios whereas the landscape connectivity of nonfractal scenarios is mainly improved by the planning rule \#1 'Proximity to built-up and open spaces'. The assessment 
of the landscape connectivity for each scenario is only global. It would be worthwhile to compare more accurately the simulated landscapes by analyzing barrier effects of roads, identifying local variations of connectivity within each landscape, and distinguishing different aspects of landscape connectivity (e.g. loss of landscape traversability versus loss of habitat patch area).

Our research gave some insight on how to combine the well-being of animals and humans with the aim of an urban sustainable development. Factors of human residential satisfaction that have been taken into account are the proximity to both green areas and other individuals. The results obtained suggest that a single optimal solution for landscape and urban planning does not exist. The choice of a solution (here one form of residential development associated with one or two planning rules) will necessarily result from a compromise. The difficulty to reach a compromise will increase if more types of ecological organisms (e.g. plants) and a higher diversity of human needs (e.g. access to local and central services) are taken into account.

\section{Acknowledgments}

The software application MUP-City has been developed in the framework of the French program PREDIT (research program on innovation in transport), funded by the French Ministry of Ecology, Energy, Sustainable Development and Sea. The graph analysis was conducted using the software 'Graphab', developed by Gilles Vuidel (UMR 6049 ThéMA), in the framework of the Graphab project of the USR 3124 MSHE Ledoux, funded by the French Ministry of Ecology, Energy, Sustainable Development and Sea. Computations have been performed on the supercomputer facilities of the Mésocentre de calcul de Franche Comté. We thank Raanan Barzel for his carefully review of the English writing.

\section{References}

1. Aguilera, F., Valenzuela, L., Botequilha-Leitão, A., 2011. Landscape metrics in the analysis of urban land use patterns: a case study in a Spanish metropolitan area. Landscape Urban Plan. 99, 226-238.

2. Alberti, M., 2005. The effects of urban patterns on ecosystem function. Int. Regional Sci. Rev. 28, 168-192.

3. Barnsley, M., 1988. Fractals everywhere, Academic Press, New York.

4. Batty, M., Xie, Y., 1996. Preliminary evidence for a theory of the fractal city. Environ. Plan. A. 28, 1745-1762. 
5. Belisle, M., 2005. Measuring landscape connectivity: the challenge of behavioral landscape ecology. Ecology. 86, 1988-1995.

6. Benguigui, L., Czamanski, D., Marinov, M., Portugali, Y., 2000. When and where is a city fractal? Environ. Plan. B. 27, 507-519.

7. Breheny, M.J., 1992. Contradictions of the compact city: a review. In: Breheny, M. J. (Ed), Sustainable Development and Urban Form, pp. 138-159.

8. Calabrese, J., Fagan, W., 2004. A comparison-shopper's guide to connectivity metrics. Frontiers in ecology and the environment. 2, 529-536.

9. Camagni, R., Gibelli, M., Rigamonti, P., 2002. Urban mobility and urban form: the social and environmental costs of different patterns of urban expansion. Ecol. Econ. 40, 199-216.

10. Caruso, G., Peeters, D., Cavailhès, J., Rounsevell, M., 2007. Spatial configurations in a periurban city. a cellular automata-based microeconomic model. Reg. Sci. Urban Econ. 37, 542-567.

11. Cavailhès, J., Frankhauser, P., Peeters, D., Thomas, I., 2004. Where Alonso meets Sierpinski: an urban economic model of fractal metropolitan area. Environ. Plan. A. 36, 1471-1498.

12. Coffin, A., 2007. From roadkill to road ecology: a review of the ecological effects of roads. J. Transp. Geogr. 15, 396-406.

13. Dantzig, G., Saaty, T., 1973. Compact city: a plan for a liveable urban environment, Freeman, San Francisco.

14. De Keersmaecker, M., Frankhauser, P., Thomas, I., 2003. Using fractal dimensions for characterizing intra-urban diversity. the example of Brussels. Geogr. Anal. 35, 310-328.

15. Fall, A., Fortin, M., Manseau, M., O’Brien, D., 2007. Spatial graphs: principles and applications for habitat connectivity. Ecosystems. 10, 448-461.

16. Forman, R., 1995. Land mosaics, the ecology of landscapes and regions, Cambridge University Press, .

17. Forman, R., Alexander, L., 1998. Roads and their major ecological effects. Annu. Rev. Ecol. Syst. 29, 207-231.

18. Frankhauser, P., 2004. Comparing the morphology of urban patterns in Europe: a fractal approach, In: Borsdorf, A., Zembri, P. (Eds.), European cities - insights on outskirts. Brussels, pp. 79-105.

19. Galpern, P., Manseau, M., Fall, A., 2011. Patch-based graphs of landscape connectivity: a guide to construction, analysis and application for conservation. Biol. Conserv. 144, 44-55.

20. Gardner, R., 1999. Rule: map generation and spatial analysis program, In: Klopatek, J., Gardner, R. (Eds.), Landscape ecological analysis: issues and applications. SpringerVerlag, New York, pp. 280-303.

21. Gardner, R., Milne, B., Turnei, M., O'Neill, R., 1987. Neutral models for the analysis of broad-scale landscape pattern. Landscape Ecol. 1, 19-28.

22. Gardner, R., Urban, D., 2007. Neutral models for testing landscape hypotheses. Landscape 
Ecol. 22, 15-29.

23. Geurs, K.T., van Wee, B., 2006. Ex-post evaluation of thirty years of compact urban development in the Netherlands. Urban Stud. 43, 139-160.

24. Hagen-Zanker, A., Lajoie, G., 2008. Neutral models of landscape change as benchmarks in the assessment of model performance. Landscape Urban Plan. 86, 284-296.

25. Herold, M., Couclelis, H., Clarke, K.C., 2005. The role of spatial metrics in the analysis and modeling of urban land use change. Comput. Environ.Urban. 29, 369-399.

26. IUCN 2010. IUCN Red List of Threatened Species. Version 2010.4. $<$ http://www.iucnredlist.org > . Accessed on 27 October 2010

27. Magle, S., Theobald, D., Crooks, K., 2009. A comparison of metrics predicting landscape connectivity for a highly interactive species along an urban gradient in Colorado, USA. Landscape Ecol. 24, 267-280.

28. Malanson, G., 2002. Extinction-debt trajectories and of habitat destruction spatial patterns. Ann. Assoc. Am. Geogr. 92, 177-188.

29. Mandelbrot, B., 1982. The fractal geometry of nature, Freeman, San Francisco.

30. Milne, B., 1991. The utility of fractal geometry in landscape design. Landscape Urban Plan. 21, 81-90.

31. Minor, E., Lookingbill, T., 2010. A multiscale network analysis of protected-area connectivity for mammals in the United States. Conserv. Biol. 24, 1549-1558.

32. Minor, E., Urban, D., 2007. Graph theory as a proxy for spatially explicit population models in conservation planning. Ecol. Appl. 17, 1771-1782.

33. Mitsova, D., Shuster, W., Wang, X., 2011. A cellular automata model of land cover change to integrate urban growth with open space conservation. Landscape Urban Plan. 99, 141153.

34. Ostapowicz, K., Vogt, P., Riiters, K., Kozak, J., Estreguil, C., 2008. Impact of scale on morphological spatial pattern of forest. Landscape Ecol. 23, 1107-1117.

35. Rayfield, B., Fortin, M-J., Fall, A., 2010. The sensitivity of least-cost habitat graphs to relative cost surface values. Landscape Ecol. 25, 519-532.

36. Riitters, K., Vogt, P., Soille, P., Estreguil, C., 2009. Landscape patterns from mathematical morphology on maps with contagion. Landscape Ecol. 24, 699-709.

37. Riitters, K., Vogt, P., Soille, P., Kozak, J., Estreguil, C., 2007. Neutral model analysis of landscape patterns from mathematical morphology. Landscape Ecol. 22, 1033-1043.

38. Saupe, D., 1988. Algorithms for random fractals., In: Petigen, H., Saupe, D. (Eds.), The science of fractal images. Springer-Verlag, New York, pp. 71-113.

39. Saura, S., Pascual-Hortal, L., 2007. A new habitat availability index to integrate connectivity in landscape conservation planning: comparison with existing indices and application to a case study. Landscape Urban Plan. 83, 91-103.

40. Saura, S., Rubio, L., 2010. A common currency for the different ways in which patches and links can contribute to habitat availability and connectivity in the landscape. Ecography. 
33, 523-537.

41. Soille, P., Vogt, P., 2009. Morphological segmentation of binary patterns. Pattern Recogn. Lett. 30, 456-459.

42. Spear, S., Balkenhol, N., Fortin, M., McRae, B., Scribner, K., 2010. Use of resistance surfaces for landscape genetic studies: considerations for parameterization and analysis. Mol. Ecol.. 19, 3576-3591.

43. Syphard, A., Clarke, K., Franklin, J., 2005. Using a cellular automaton model to forecast the effects of urban growth on habitat pattern in southern California. Ecological complexity. 2, 185-203.

44. Tannier, C., Vuidel, G., Frankhauser, P., Houot, H., 2010. Simulation fractale d'urbanisation - mup-city, un modèle multi-échelle pour localiser de nouvelles implantations résidentielles. Revue Internationale de géomatique. 20, 303-329.

45. Taylor, P.D., Fahrig, L., With, K.A., 2006. Landscape connectivity: a return to basics, In: Crooks, K.R., Sanjayan, M. (Eds.), Connectivity conservation. Cambridge University Press, Cambridge, UK, pp. 29-43.

46. Termorshuizen, J., Opdam, P., van den Brink, A., 2007. Incorporating ecological sustainability into landscape planning. Landscape Urban Plan. 79, 374-384.

47. Thomas, I., Frankhauser, P., Biernacki, C., 2008. The morphology of built-up landscapes in Wallonia (Belgium): a classification using fractal indices. Landscape Urban Plan. 84, 99115.

48. Tischendorf, L., Fahrig, L., 2000. How should we measure landscape connectivity? Landscape Ecol. 15, 633-641.

49. Tratalos, J., Fuller, R., Warren, P., Davies, R., Gaston, K., 2007. Urban form, biodiversity potential and ecosystem services. Landscape Urban Plan. 83, 308-317.

50. Urban, D., Keitt, T., 2001. Landscape connectivity: a graph-theoretic perspective. Ecology. 82, 1205-1218.

51. Vasas, V., Magura, T., Jordán, F., Tóthmérész, B., 2009. Graph theory in action: evaluating planned highway tracks based on connectivity measures. Landscape Ecol. Report, 6 p.

52. Vogt, P., Ferrari, J., Lookingbill, T., Gardner, R., Riitters, K., Ostapowicz, K., 2009. Mapping functional connectivity. Ecol. Indic. 9, 64-71.

53. Vogt, P., Riitters, K., Iwanowski, M., Estreguil, C., Kozak, J., Soille, P., 2007. Mapping landscape corridors. Ecol. Indic. 7, 481-488.

54. Wickham, J., Riitters, K., Wade, T., Vogt, P., 2010. A national assessment of green infrastructure and change for the conterminous united states using morphological image processing. Landscape Urban Plan. 94, 186-195.

55. With, K., Crist, T., 1995. Critical thresholds in species' responses to landscape structure. Ecology. 76, 2446-2459.

56. Zetterberg, A., Mortberg, U.M., Balfors, B., 2010. Making graph theory operational for landscape ecological assessments, planning, and design. Landscape Urban Plan. 95, 181191. 